Research Article

\title{
Thermal Conductivity Characteristics of Thermal Insulation Materials Immersed in Water for Cold-Region Tunnels
}

\author{
Youyun Li (D), Yongmei Sun (D), Yuan Zhuang, LiMin Duan (D), and Ke Xie \\ Key Laboratory of Special Area Highway Engineering, Ministry of Education, Chang'an University, Xi'an 710064, China \\ Correspondence should be addressed to Youyun Li; liyouyun2006@chd.edu.cn and Yongmei Sun; 1433443208@qq.com
}

Received 30 May 2019; Revised 27 December 2019; Accepted 15 February 2020; Published 9 April 2020

Academic Editor: Saliha Ilican

Copyright (C) 2020 Youyun Li et al. This is an open access article distributed under the Creative Commons Attribution License, which permits unrestricted use, distribution, and reproduction in any medium, provided the original work is properly cited.

\begin{abstract}
This study investigates the distribution of pore water on the basis of the measured mass moisture content after soaking the tunnel insulation material. This study also analyzes the influence of the distribution of pore water on the thermal conductivity of the material on the basis of this mass moisture content. Scanning images of phenolic and polyurethane insulation boards are obtained by computer tomography (CT). The gray volume moisture content (Gv) is deduced based on the CT scanning images, to determine the distribution of pore water ( $\mathrm{Gv}$ is the ratio of the volume of the water sample (represented by the gray value) to the volume of the saturated water sample (represented by the gray value) which is the gray volume moisture content of the sample). The correlation between gray volume moisture content and mass moisture content is determined by comparing different algorithms of gray volume moisture content and volume moisture content. The relationship between mass moisture content and thermal conductivity can be determined using a self-made quasi-steady-state tester, whereas the relationship between gray volume moisture content and thermal conductivity can be derived indirectly. Related experimental research can predict the thermal conductivity of thermal insulation materials by using a new perspective and shows the influence of pore water distribution on the thermal conductivity of materials.
\end{abstract}

\section{Introduction}

The rapid development of transportation systems has led to progressive growth of tunnel construction in cold regions; however, damage caused by freezing of tunnels constructed in cold regions also commonly occurs [1-5]. Problems associated with frost damage, including lining leakage, spalling of lining, frost heave of the surrounding rock, and watering and freezing of the road surface, often render the tunnel unusable from August to September annually, significantly affecting the efficiency of the tunnel [6-10]. The typical engineering solution to tunnel frost damage in cold regions is laying a thermal insulation layer [11-14]. Numerous studies have been conducted on the influence of various factors on thermal insulation layer [15-18]. In accordance with the principle of thermal insulation for permafrost protection, Cheng expounded on the applicability of various thermal insulation layers [19]. Xia combined theoretical analysis with finite element simulation to calculate the thickness of the insulation layer applied to various frozen soils by $[20,21]$. The effect of the thickness and length of an insulation layer on the temperature field of a tunnel in a cold area was analyzed based on the two-dimensional finite element model [22]. Using numerical simulation, Qi determined the relationship between the freeze-thaw range and the thickness of thermal insulation materials on the basis of the variation law of the freeze-thaw range of different thermal insulation materials $[23,24]$. Yan examined the effects of variations in mechanical ventilation speed and different cold regions on the design of the thermal insulation layer on the basis of the numerical mode $l[25,26]$. Li emphasized the effects of soil temperature and moisture content around the tunnel on the optimal thickness of the tunnel insulation layer [27-29].

The thermal insulation performance index of a thermal insulation material is mainly determined by thermal conductivity [30-32]. Ma proposed that the thermal conductivity of a thermal insulation material is as important as its 
thickness in the design and construction of tunnels in cold regions [33]. By establishing a numerical coupled hotmoisture model of a tunnel in a seasonally frozen zone, Ma established a method for calculating the thermal conductivity and thickness of the thermal insulation layer and determined the relationship between thermal insulation effect and thermal conductivity combined with the thickness of the thermal insulation layer. Several studies on the thermal conductivity of some building materials have also been conducted. Zahia deduced the predictive analysis of the effective thermal conductivity of fiber-containing mortar composites by using experimental results and a theoretical model [34]. Lahcen evaluated the variation in thermal conductivity of date palm fiber (DPF) mesh plates, DPFs, and mud composites with water content and then determined the intrinsic thermal conductivity of the DPF and mortar by using the best-fitting model [35]. Pavlšk placed bricks in tunnels between climatic chambers with different temperatures and calculated the thermal conductivity of bricks by using the semi-scale steady-state experimental method and measured data [36]. Bodnarova used the hot wire method to measure the thermal conductivity in the unsteady state and evaluated the temperature dependence of the thermal conductivity of lightweight concrete [37]. However, in the current study, most tunnel thermal insulation materials evaluate the influence of length, thickness, and other factors and rarely investigate the thermal conductivity of the material itself. Numerous studies have been conducted on the thermal conductivity of building insulation materials. However, these reports mostly examine the influence of water content on the materials and rarely explore the influence of water distribution on the thermal conductivity of materials. In the present study, gray volume moisture content $(\mathrm{Gv})$ is defined, and the relationship between $\mathrm{Gv}$ and mass moisture content is established. On the basis of the relationship between mass moisture content and thermal conductivity, the relationship between gray volume moisture content and thermal conductivity is established to better describe the influence of pore water distribution on thermal conductivity. This study is highly valuable and can be used to address concerns related to thermal insulation materials in cold-region tunnels.

\section{Experimental Designs}

2.1. Test Materials. Phenolic insulation boards, polyurethane insulation boards, and floquet insulators are some of the most common thermal insulation materials used in tunnels, hence their selection as research objects for conducting experimental analysis. The insulation material used in the test is shown in Figure 1, measuring $98 \mathrm{~cm} \times 98 \mathrm{~cm} \times 50 \mathrm{~cm}$ (length $\times$ width $\times$ height) [38]. The physical indices of the specimens are listed in Table 1 . The polyurethane insulation board has a smooth waterproofing layer on one side and a rough one on the other. The waterproofing layer, which influences the water absorption of polyurethane materials, has irregular holes on the surface. Thus, the waterproof layer on the surface of the polyurethane insulation board was removed to study the variation in moisture content with time under the most disadvantageous conditions.

\subsection{Test Equipment}

2.2.1. Water Absorption Testing Equipment. The water absorption device is divided into two types: the natural active water absorption device and the pressure passive water absorption device (Figure 2). The natural active water absorption device simulates the one-sided active water absorption of the insulation material in a natural state when leakage occurs in tunnels in cold regions [39]. The water container on the left side of this device is connected via a rubber pipe to the funnel on the right side to form a connector, which ensures that the two liquid levels are of the same height. The influence of water head pressure on the water absorption of the insulating layer material is simulated by a pressurized passive water absorption device. The main body of the device is a pressure cylinder connected to two rubber tubes-an intake pipe and a communicating pipe. The installation of the connecting pipe is conducive to gas discharge when the device absorbs water and facilitates the irrigation process.

\subsubsection{CT Scanning Test Equipment}

(1) Testing Instrument. The $225 \mathrm{kV}$ X-ray industrial CT (Yxlon, Germany) is shown in Figure 3. Relevant parameters are listed in Table 2.

(2) Working Principle of the X-Ray Industrial CT. As shown in Figure 3, the X-ray emitted from the X-ray source scans the detected object in translational motion between the $\mathrm{X}$-ray source and the detector. After scanning, the object is rotated at an angle and then scanned again. By repeated operation, several datasets of a certain section of the detected object can be obtained. These data are computed and processed by a computer. An image of the complete section is reconstructed and displayed on the monitor. All sections can form a complete three-dimensional image.

The CT image is a gray image, with each pixel corresponding to a CT number showing different gray levels. The higher the density of the scanned material, the higher the brightness of the image. Therefore, in the analysis of this image obtained by CT scanning the aquifer thermal insulation sample, the black area represents the pore, the lighter area is the dry sample without water, and the white area is the water absorption area.

\subsubsection{Thermal Conductivity Testing Device}

(1) Hot Disk TPS 2500 S Thermophysical Conductivity Analyzer. The thermophysical conductivity analyzer (Figure 4) (Hot Disk, Sweden) mainly consists of the test system, the calculator, and the data recording system (computer). The Hot Disk tester is a double-helix sensor, which is often a nickel-metal double helix with a thickness of 25 microns. It is 

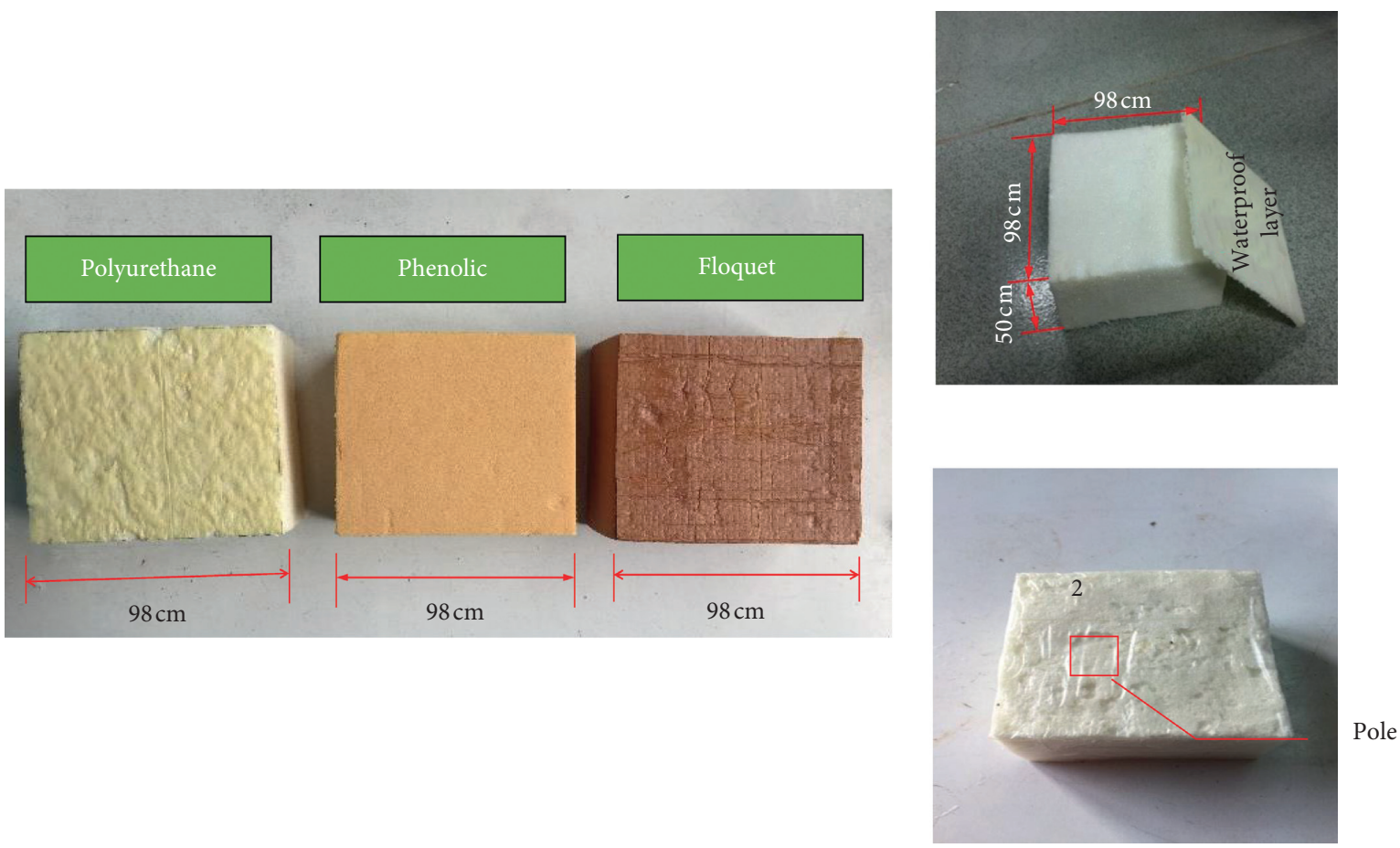

FIGURE 1: Insulating layer material sample.

Table 1: Physical indexes of the thermal insulation layer material.

\begin{tabular}{lcccccc}
\hline Name & Density $\left(\mathrm{kg} / \mathrm{m}^{3}\right)$ & $\begin{array}{c}\text { Thermal conductivity } \\
(\mathrm{W} /(\mathrm{m} \cdot \mathrm{K}))\end{array}$ & $\begin{array}{c}\text { Compressive } \\
\text { strength }(\mathrm{kPa})\end{array}$ & $\begin{array}{c}\text { Volumetric water } \\
\text { absorption }(\%)\end{array}$ & $\begin{array}{c}\text { Fireproof } \\
\text { performance }(\text { rank })\end{array}$ & $\begin{array}{c}\text { Temperature } \\
\text { range }\left({ }^{\circ} \mathrm{C}\right)\end{array}$ \\
\hline Phenolic & $40-60$ & $0.026-0.040$ & $\geq 100$ & $\leq 7.5$ & $\mathrm{~B} 1$ & $-100-180$ \\
Polyurethane & $25-55$ & $0.022-0.024$ & $\geq 150$ & $\leq 4$ & $\mathrm{~B} 2$ & $-50-100$ \\
Floquet & $30-50$ & $0.022-0.033$ & $\geq 100$ & $\leq 6$ & $\mathrm{~B} 1$ & $-196-180$ \\
\hline
\end{tabular}
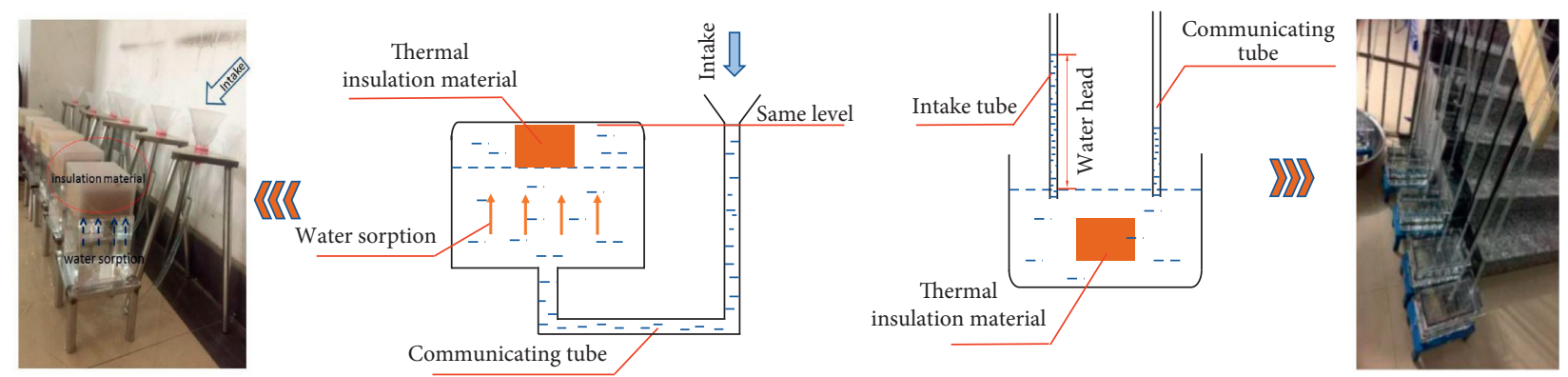

FIgURE 2: Water absorption devices.
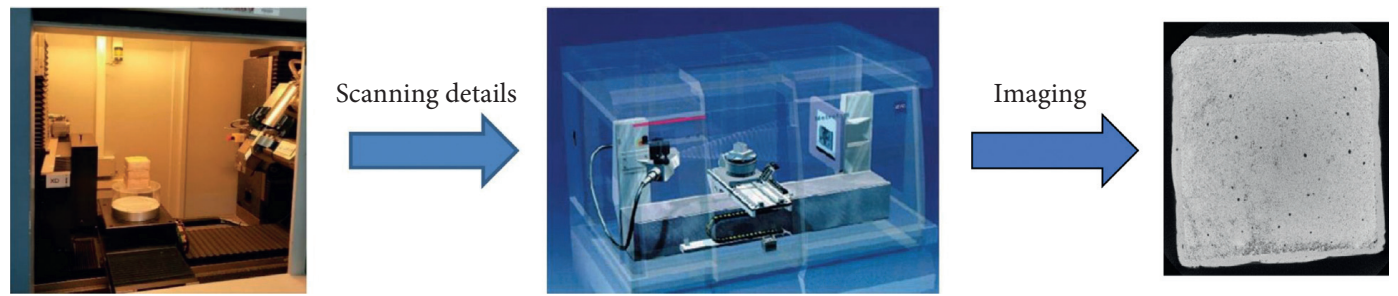

FIGURE 3: Internal structure and scanning principle of the compact-225 industrial CT. 
TABLe 2: Main technical parameters of the $225 \mathrm{kV}$ X-ray industrial CT.

\begin{tabular}{lcccccc}
\hline Name & Size & Ray source & $\begin{array}{c}\text { Imaging } \\
\text { pixel }\end{array}$ & Scanning time & $\begin{array}{c}\text { Highest spatial } \\
\text { Contrast } \\
\text { resolution (mm) }\end{array}$ & $\begin{array}{c}\text { Consitivity } \\
\text { sention }\end{array}$ \\
\hline Parameters & $170 \mathrm{~mm}$ & Ceramic metal X-ray tube & $1024 \times 1024$ & Typical high-precision scanning $5-15 \mathrm{~min}$ & 0.02 & $<0.2 \%$ \\
\hline
\end{tabular}

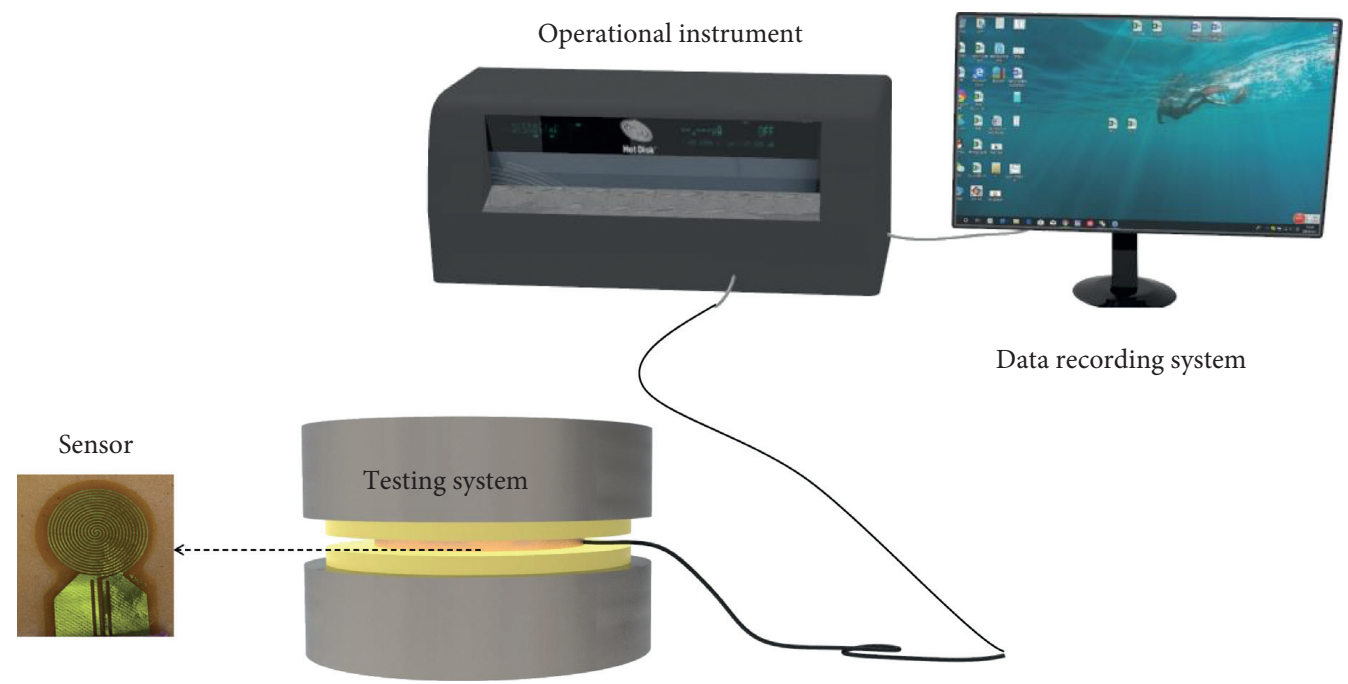

FIgURE 4: Hot Disk TPS 2500 S thermophysical conductivity analyzer.

not only a heat source for increasing temperature but also a heat flow resistor for recording changes in temperature over time. The parameters of the thermophysical conductivity analyzer are listed in Table 3.

(2) Self-Made Quasi-Steady State Tester. In accordance with the principle of quasi-steady state thermal conductivity, a thermal conductivity test device for insulating layer materials is fabricated. The device is mainly composed of a test box, a data acquisition system, and a heating system (Figure 5).

The test box is made of a polystyrene (EPS) foam board with a thickness of $10 \mathrm{~cm}$. The EPS foam board possesses good thermal insulation owing to its low thermal conductivity. As the main part of the test box, it can effectively isolate the heat exchange between the sample and the surrounding environment during testing and reduce the test error. The space in the test box measures $300 \mathrm{~mm} \times$ $300 \mathrm{~mm} \times 200 \mathrm{~mm}$.

The data acquisition system consists of a paperless recorder and a temperature sensor, which are used to measure the temperature of the sample in real time. The accuracy of the paperless recorder can reach $2 \%$, and the temperature of one decimal point is displayed. The PT100 temperature sensor with a small volume and four wires is selected as the temperature sensor. The probe is $3 \mathrm{~mm}$ in diameter, $10 \mathrm{~mm}$ in length, and $0.15^{\circ} \mathrm{C}$ in precision.

The heating system is composed of a heating sheet, pure copper sheet, and a power supply, which allow the system to provide a stable heat flow to the system. The heating element consists of a $\mathrm{Ni}-\mathrm{Cr}$ electric heating wire and a polyimide heating film with a thickness of $0.4 \mathrm{~mm}$, length of $300 \mathrm{~mm}$, and width of $300 \mathrm{~mm}$. A pure copper sheet with high thermal conductivity is placed on the upper and lower surfaces of the heating sheet, rendering the surface temperature of the heating sheet uniformly distributed. The power supply adopts adjustable DC voltage-stabilized power supply, with voltage ranging from 0 to $30 \mathrm{~V}$ and current ranging from 0 to $10 \mathrm{~A}$.

(3) Electric Heating Temperature Blast Dryer. The DB-250B electric heating temperature blast dryer (Hong Xing Electric Oven Factory, Chengdu) is typically used for sample drying, heat treatment, and other heating purposes. The main technical parameters are listed in Table 4.

\subsection{Test Processes}

2.3.1. Water Absorption Test and CT Scan. In order to simulate the water absorption of thermal insulation material in cold region tunnel and determine the maximum mass moisture content of various insulation panels under different water absorption conditions, three kinds of insulation panels were selected: the phenolic insulation board, polyurethane insulation board, and floquet insulation panels. Natural active water absorption test and pressure passive water absorption test were conducted, with a one-day interval in the initial stage and a two-day interval in the subsequent stage. In order to carry out comparative analysis, a set of complete immersion test is added. The test could be terminated when the difference between two successive measurements was less than $0.5 \%$ of the value of the second test.

By using the aforementioned process, the water absorption rate of the peeled polyurethane insulation board 
TABLE 3: Parameters of the thermophysical property analyzer.

\begin{tabular}{|c|c|c|c|c|}
\hline Name & Measuring range & $\begin{array}{l}\text { Temperature } \\
\text { range }\end{array}$ & $\begin{array}{l}\text { Range of thermal } \\
\text { conductivity }\end{array}$ & Probe size \\
\hline $\begin{array}{l}\text { Hot disk TPS2500s thermophysical conductivity } \\
\text { analyzer }\end{array}$ & $\begin{array}{l}0.005-500 \mathrm{~W} / \\
(\mathrm{m} \cdot \mathrm{K})\end{array}$ & $10-1000 \mathrm{~K}$ & $0.005-500 \mathrm{~W} /(\mathrm{m} \cdot \mathrm{K})$ & $2-29.40 \mathrm{~mm}$ \\
\hline
\end{tabular}

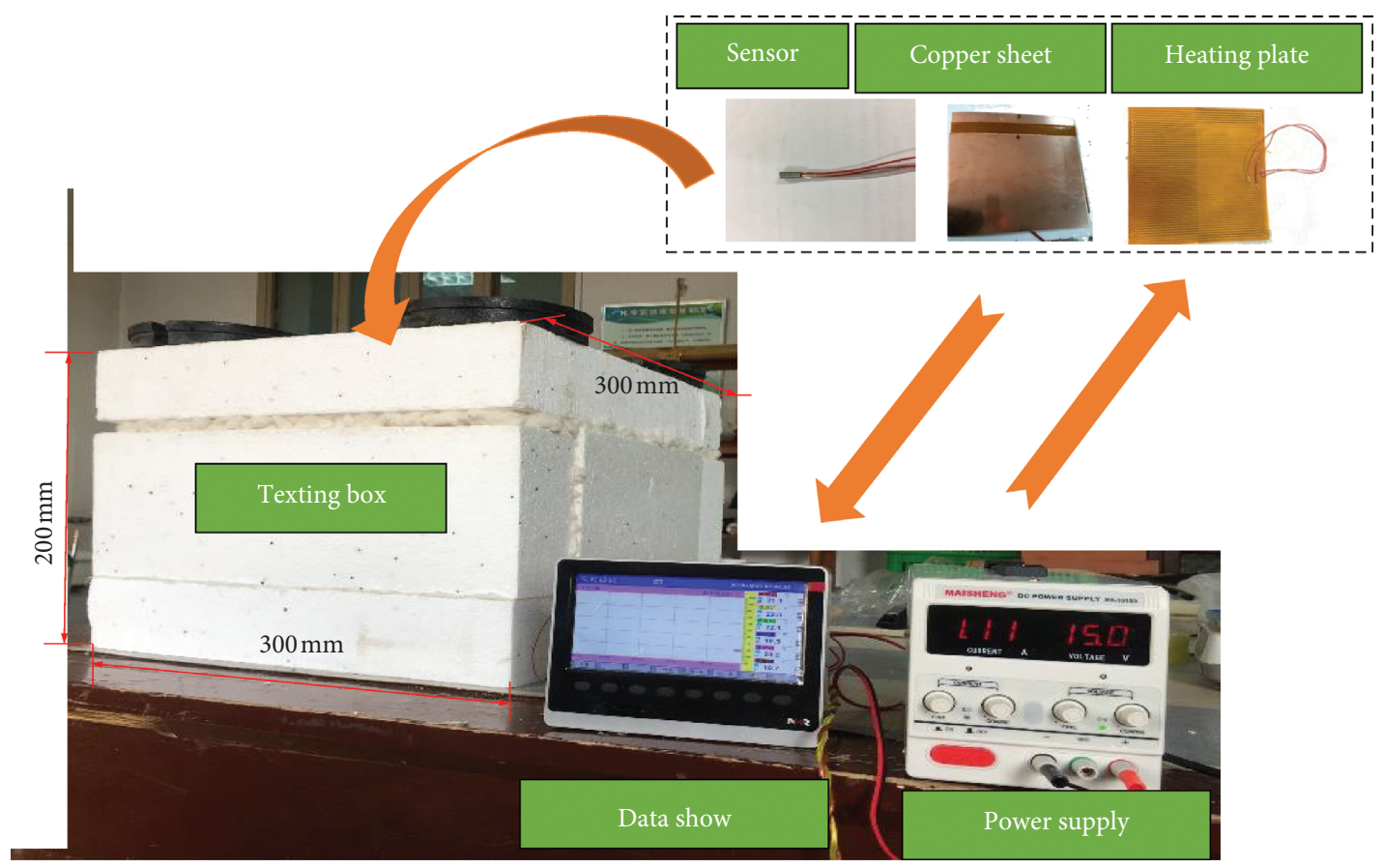

FIgURE 5: Self-made quasi-steady state tester.

TABle 4: Main technical parameters of the DB-250B electric heating temperature blast dryer.

\begin{tabular}{lccc}
\hline Name & Size & Temperature range & Sensitivity \\
\hline Parameters & $500 \mathrm{~mm} \times 600 \mathrm{~mm} \times 750 \mathrm{~mm}$ & Room temperature $\sim 250^{\circ} \mathrm{C}$ & $\pm 0.1^{\circ} \mathrm{C}$ \\
\hline
\end{tabular}

was determined to be lower, whereas that of the phenolic insulation board was higher. Therefore, three peeled polyurethane insulation panels with different mass moisture contents and six phenolic insulation panels with different mass moisture contents were obtained by using the passive water absorption test under pressure, which was conducted by controlling different water absorption periods. The samples with different mass moisture contents are listed in Table 5 .

The maximum allowable external diameter of the sample was $170 \mathrm{~mm}$. A sample size of less than $140 \mathrm{~mm}$ produced the best scanning effect. Therefore, to reduce costs, three samples with different mass moisture contents were stacked to optimize the use of the scanning space. The scanning image of the phenolic insulation board is presented in Figure 6.

2.3.2. Measurement of Thermal Conductivity. The Hot Disk method is suitable for homogeneous media but not for containing water sample in this test. Therefore, the Hot Disk method was chosen to test samples in their absolutely dry state. The quasi-steady-state heat conduction test was used for stratified aqueous samples, and the results for the test sample in their absolute dry state were compared with those obtained using the Hot Disk method.

(1) Hot Disk Method. The dry phenolic insulation board and peeled polyurethane insulation board were selected as test sample. The encapsulated nickel spiral sensor was sandwiched between the two parts for testing, and the protective cover was placed. The sensor heating power and time were set on the computer. The Hot Disk test software was run, and the corresponding test module was selected. Testing was then started. When the number of test points needed was subsequently selected, the thermal conductivity coefficient was calculated using the system software, with the time interval between the two tests set at $1.5 \mathrm{~h}$.

(2) Quasi-Steady Testing Method. Sample preparation was conducted in accordance with "Highway Geotechnical Test Rules” (JTG E40-2007). Phenolic and polyurethane 
TABLE 5: Mass moisture contents of the insulation layer material.

\begin{tabular}{lccc}
\hline Name & & Mass moisture content (\%) & \\
\hline Peeled polyurethane & 9.80 & 14.74 & 25.23 \\
Phenolic & 808.78 & 921.64 & 1632.53 \\
Phenolic & 2782.25 & 3080.29 & 3763.91 \\
\hline
\end{tabular}

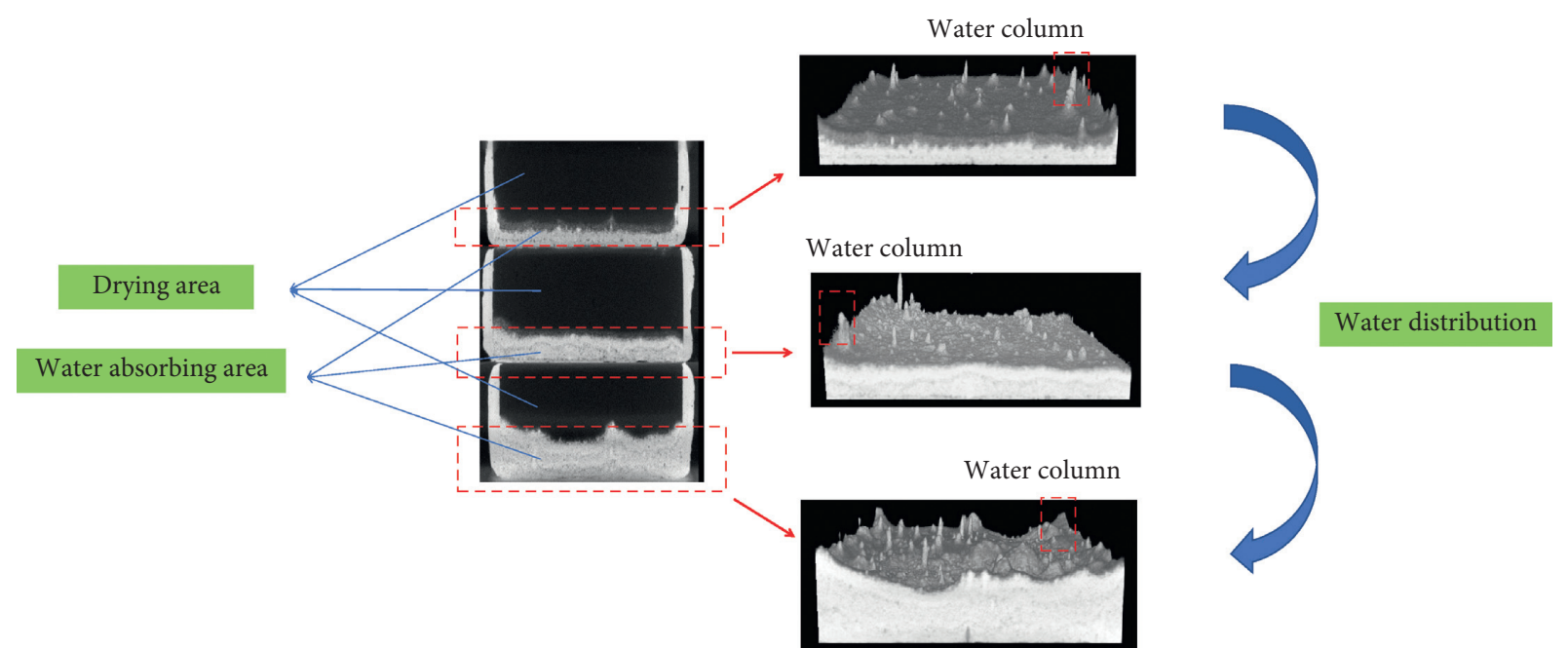

FIgURE 6: CT scanning image of the phenolic insulation plate sample in three directions.

insulation boards with different moisture contents were obtained. Four samples of the same size, material, and moisture contents were placed in the test box (reducing the test error) after the temperature sensor was affixed to them and numbered 1, 2, 3, and 4 from the bottom to the top. The heating device was placed between the test pieces 1 and 2 and test pieces 3 and 4 . The test box was then sealed, the paperless recorder and DC-regulated power supply were turned on, and the test began. When the difference in temperature between the upper and lower surfaces of sample 2 decreased, the test was stopped, and one test was completed.

\section{Test Results and Analysis}

3.1. Maximum Mass Moisture Content of the Thermal Insulation Material. Figure 7 shows that, under natural active water absorption, the growth rate of mass moisture content gradually slows down over time. In the early stages of water absorption, the phenolic insulation board had the largest water absorption rate, followed by the floquet insulation board and peeled polyurethane insulation board. Simultaneously, with an increase in time, the mass moisture content of the phenolic insulation board and floquet insulation board grew gradually closer, with the mass moisture content of the phenolic insulation board being consistently greater than that of the floquet insulation board within the test time range. After testing for 5 months, the increase in amplitude of the mass moisture content of the floquet insulation board was twice that of the phenolic insulation board; thus, the mass moisture content of the floquet insulation board was gradually close to that of the phenolic insulation board.

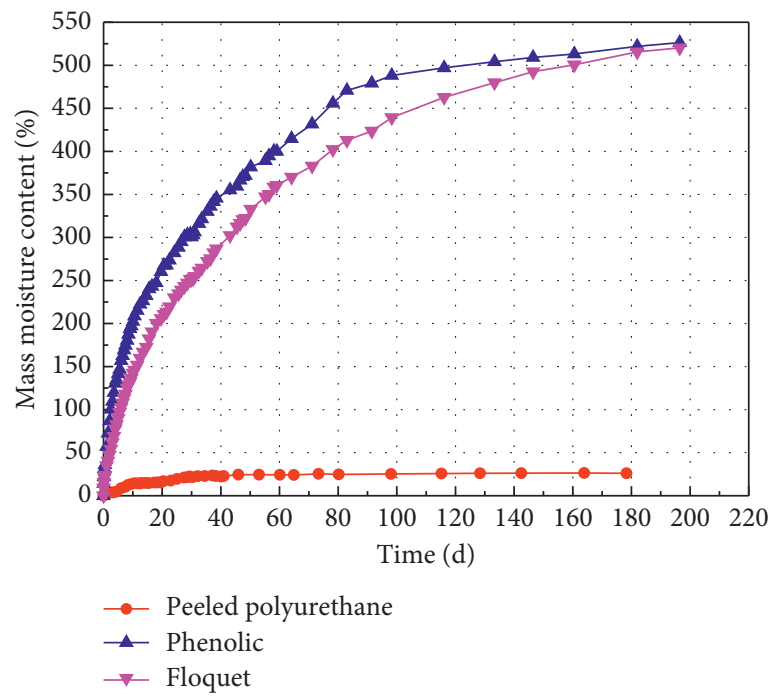

FIgURE 7: Curve of the water content of the thermal insulation material with time after natural active water absorption.

Therefore, when the test period reaches at least 7 months, the moisture content of the floquet insulation board is temporarily greater than that of the phenolic insulation board.

Completely immersed in water, the phenolic insulation board, peeled polyurethane insulation board, and floquet insulation board showed mass moisture contents of $2347.58 \%$, 92.91\%, and $850 \%$, respectively (Figure 8 ). The mass moisture content of the phenolic insulation board was 25.27 times that of the peeled polyurethane insulation board 
and 2.71 times that of the floquet insulation board. Among the three kinds of insulation boards, the phenolic insulation board exhibited the best absorption.

Figure 9 presents the time-dependent curve of the mass moisture content absorbed by different thermal insulation materials via passive water absorption under different water pressure levels. The curve trend shows that the mass moisture content is at its highest in the early stage of water absorption; over time, the rate of moisture absorption decreases and ultimately stabilizes. When the test is stable, the mass moisture content of the specimens under high head pressure is greater than those under low head pressure.

In summary, the maximum mass moisture contents of the three thermal insulation materials could be obtained by experimental analysis of the three groups (Table 6).

\subsection{Relationship between Mass Moisture Content and Gray} Value. At gray value $=0$, the image is darkest and black, whereas at gray value $=255$, the image is brightest and white. The higher the density of the matter, the brighter (white) it appears in CT images; the lower the density of the matter, the darker (black) it appears. The densities are as follows: density of air, $1.225 \mathrm{~kg} / \mathrm{m}^{3}$; density of water, $1000 \mathrm{~kg} / \mathrm{m}^{3}$; apparent density of the selected phenolic insulation board, $22 \mathrm{~kg} / \mathrm{m}^{3}$; and apparent density of the polyurethane insulation board, $33.8 \mathrm{~kg} / \mathrm{m}^{3}$. Water evidently exhibits the highest density. Thus, its distribution in the insulation material can be easily distinguished by CT scanning test. At moisture content $=0 \%$, the gray level histogram shows a single-peak image. When the phenolic insulation board absorbs water, two peaks appear in the gray histogram. The density of water is considerably higher than that of the dry phenolic insulation board and thus can be expressed using the gray value. Therefore, the wave peak at the lower gray value consists of the gray value of the pixel where the dry phenolic insulation board is located, whereas the wave peak at the higher gray value consists of the gray value of the pixel where the phenolic insulation board after water absorption is located.

3.2.1. Phenolic Insulation Board. Dry samples and aqueous samples are scanned separately. Figure 10 shows that when scanning dry samples, the gray values range from 6 to 115 , whereas when scanning water-bearing samples, the gray values range from 0 to 255, comprising all gray values. For the water-containing phenolic insulation board, when the gray value is less than or equal to 65 , no water is found in the interior of the phenolic insulation board; meanwhile, for the image with a bit depth of 8 , the maximum gray value is 255 . Therefore, in the CT scan image of the phenolic insulation board, when the gray value is in the 65-255 range, it is a mixture of water and the phenolic insulation material; when the gray value is 255 , the mass moisture content of the pixel reaches saturation. In addition, when the gray value is 65 , the water content is $0 \%$. The gray value of the water-containing thermal insulation material from 65 to 255 is divided into 100 copies; that is, when the mass moisture content of a pixel increases by $1 \%$, the gray value of the point increases by 1.9 .

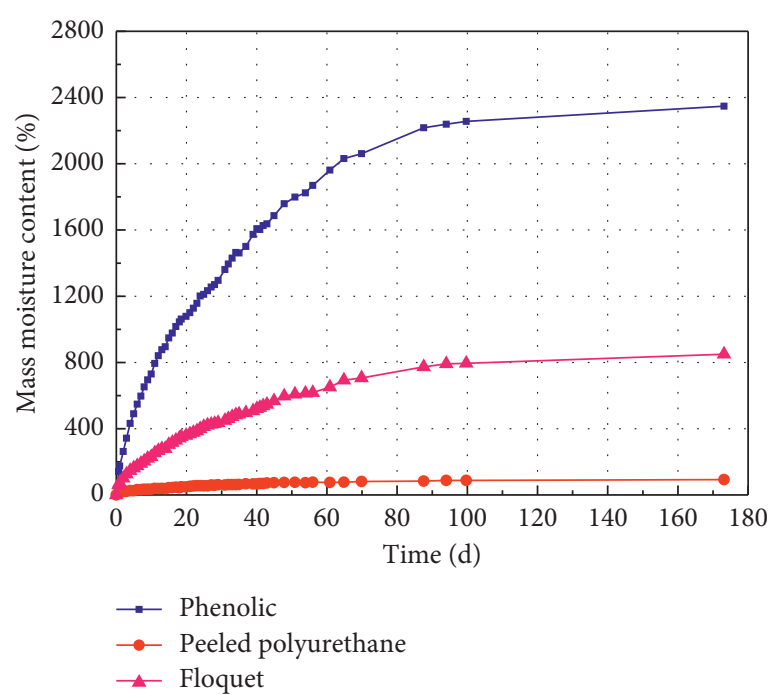

FIGURE 8: Curve of the water content of the thermal insulation layer material with time after complete immersion.

Therefore, the gray value can be used to quantitatively describe the saturation of the material. For the waterbearing samples, the saturation degree of individual pixels was studied. With the area of the pixel as the base, the gray value is high, and $M$ is the boundary gray value between the dry state and the water-bearing state of the material. When the gray value is less than or equal to $M$, the product of the bottom area of the pixel and the gray value represents the volume of the dried sample. When the gray value reaches the maximum $D$ of the image, the pixel is considered full of water and saturated; when the gray value is between $M$ and $D$, it is the volume of the unsaturated water-bearing sample. The area of each pixel in the image, multiplied by its own gray level, comprises a small volume; thus, by adding all small volumes in the image, the total volume of the material represented by the gray value can be obtained.

Assuming that the total number of pixels in a CT scan image is $N$, let the gray value be $i(i=0,1, \ldots, 255)$. If the number of pixels in the image with a gray value equal to $i$ is $N_{i}$, the total volume of the material represented by the gray value is as follows:

$$
G=\sum_{i=0}^{255} i \cdot N_{i} \cdot S
$$

where $S$ is the pixel area and $G$ is the volume of the water content sample expressed in gray value.

The total volume of saturated specimens expressed by gray value is as follows:

$$
G_{s}=S \cdot N \cdot D,
$$

where $D$ is maximum gray value of all pixels in an image, $0 D \leq 255 ; G_{S}$ is the volume of materials with $100 \%$ water content expressed by gray value; and $N$ is the total number of image pixels.

The image volume moisture content (gray volume moisture content) expressed by gray value is 


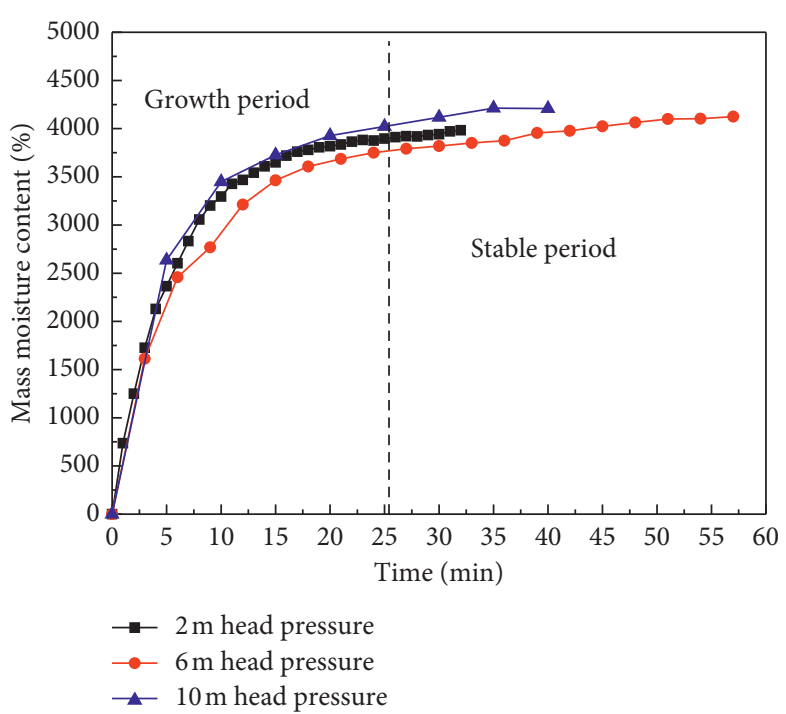

(a)

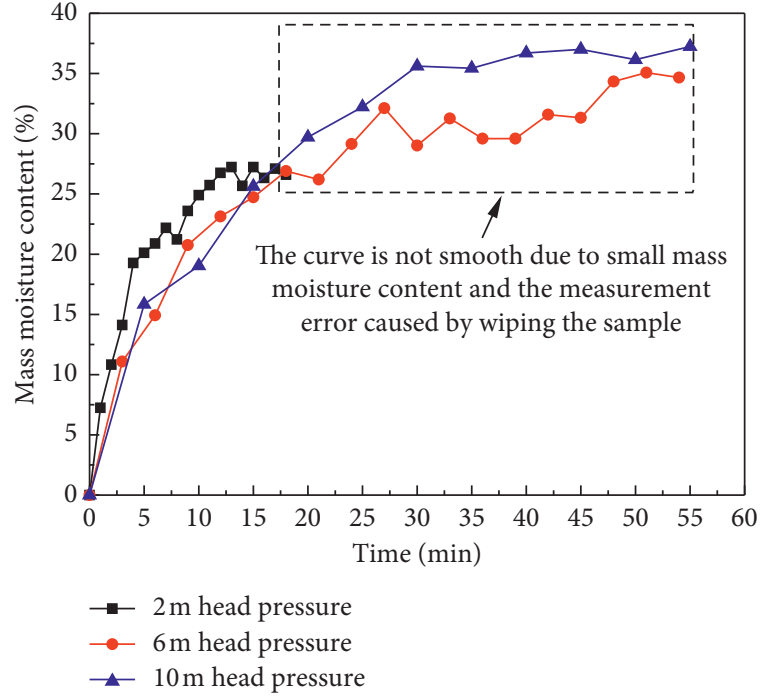

(b)

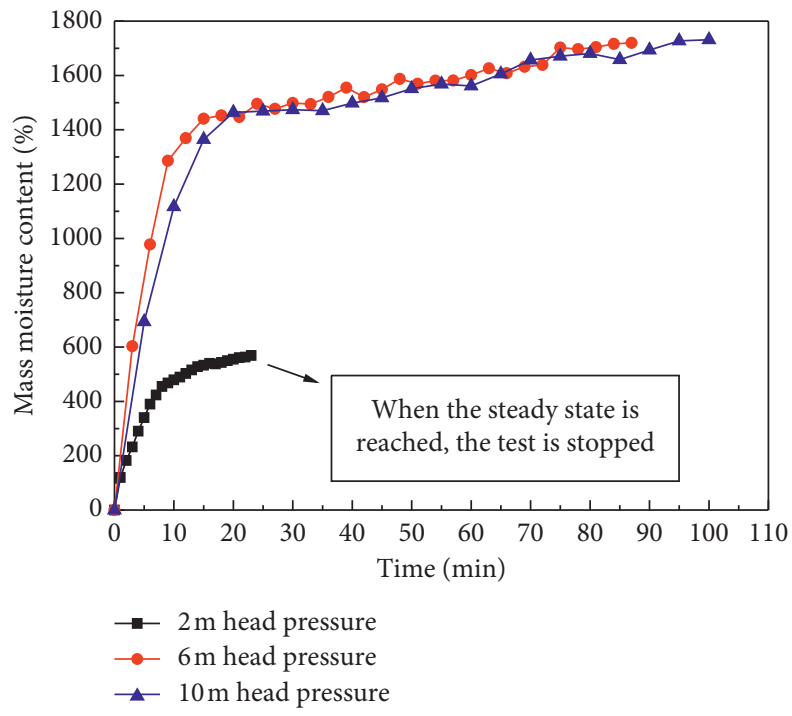

(c)

FiguRE 9: The change curve of the water content in the thermal insulation layer material over time by pressure passive water absorption. (a) Phenolic insulation board. (b) Peeled polyurethane insulation board. (c) Floquet insulation board.

TABLE 6: Maximum mass water contents of the thermal insulation layer materials.

\begin{tabular}{lccc}
\hline \multirow{2}{*}{ Name } & $\begin{array}{c}\text { Maximum mass moisture content } \\
\text { obtained using the natural active } \\
\text { water absorption test (\%) }\end{array}$ & $\begin{array}{c}\text { Maximum mass moisture content } \\
\text { obtained using the pressure passive } \\
\text { water absorption test (\%) }\end{array}$ & $\begin{array}{c}\text { Maximum mass moisture content of the } \\
\text { complete immersion test (\%) }\end{array}$ \\
\hline Phenolic & 526.28 & 4208.65 & 2347.58 \\
Peeled polyurethane & 26.04 & 37.24 & 92.91 \\
Floquet & 520.17 & 1742.50 & 850.00 \\
\hline
\end{tabular}

$$
G_{\mathrm{V}}=\frac{\sum_{i=M}^{D} i \cdot N_{i} \cdot S}{G_{S}} \times 100,
$$

where $M$ is the boundary value of the drying state and waterbearing state of materials, $0<M<255$.

The volumetric moisture content can be calculated using this algorithm, and the results are expressed as shown in Figure 11. The general algorithm and the algorithm presented in this study exhibit a similar overall trend-increasing with an increase in mass moisture content. When the mass moisture content exceeds $3500 \%$, the calculation results of the two algorithms vary to a certain degree. Generally, the calculation results (Table 7) of the volume water content expressed by gray value and calculated by mass moisture content are anastomosing. 

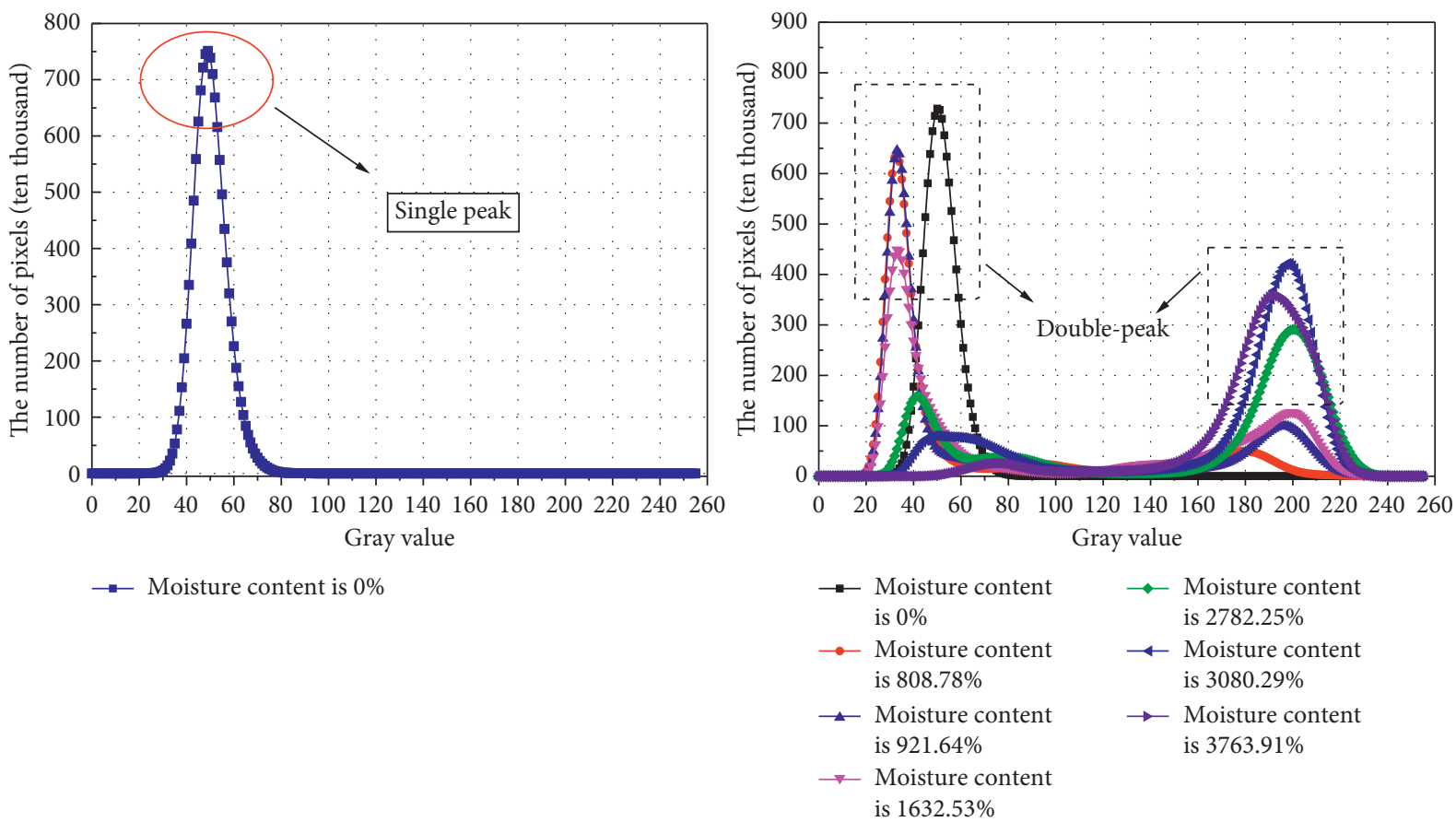

Figure 10: Gray histogram of the phenolic insulation panels with different moisture contents.

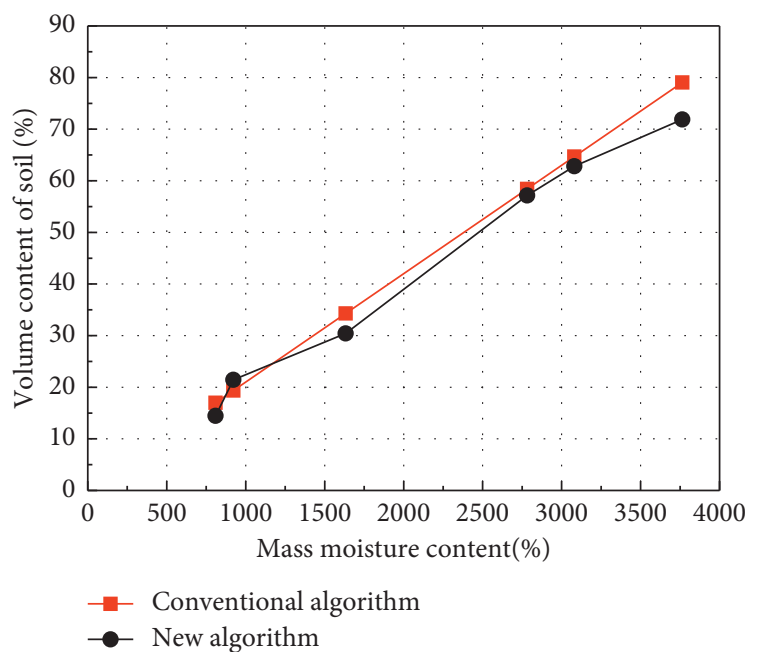

FIgURE 11: Comparison of two algorithms for the phenolic thermal insulation board.

3.2.2. Peeled Polyurethane Insulation Board. Similar to the aforementioned phenolic insulation board, the waterbearing polyurethane insulation board has a gray value distribution that ranges from 0 to 255 (Figure 12). Analysis indicates that the drying part of the water-bearing polyurethane insulation board has a gray value of less than 50 . Therefore, when the gray value ranges from 50 to 255 , the water content is mixed with polyurethane insulation materials; when the gray value is 255 , the water content of the pixel reaches saturation; and when the gray value is 50 , the water content is $0 \%$. The gray value of the thermal insulation material containing water from 50 to 255 is divided into 100 parts; that is, when the water content of a pixel increases by
$1 \%$, the gray value of the pixel increases by $2.05 \%$. Therefore, the gray value can be used to quantitatively describe the degree of saturation of the material. By using the derivative formula, the volumetric moisture content of the watercontaining polyurethane insulation board in the gray level is calculated. The results are listed in Table 8.

The volumetric moisture contents measured by the conversion of mass moisture content generally agree with the calculation results of the volumetric moisture content expressed by the gray value presented in this study. The volumetric moisture contents increase with an increase in mass moisture content.

\subsection{Relationship between the Thermal Conductivity and Mass} Moisture Content of Thermal Insulation Materials. Heat transfer through the structures of thermal insulation materials often results from several heat transfer modes that typically involve the conduction of solids, convection, and conduction of gases and heat radiation [40]. When the average diameter of particles in a porous medium does not exceed 4-6 $\mathrm{mm}$, the effect of convective heat transfer on the internal heat transfer of the material may be negligible; when the temperature of the porous material is not higher than $573 \mathrm{~K}\left(299.85^{\circ} \mathrm{C}\right)$, the effect of radiation may be negligible [41]. In the present study, the effective thermal conductivity of the thermal insulation material meets the aforementioned conditions without considering convection and radiation heat transfer. Thus, the scope of this study only covers the effect of heat conduction on the thermal conductivity of the thermal insulation material. In the analysis of the mechanism of various heat transfer processes in porous materials, the heat transfer mode of the solid skeleton and various fluids in porous materials can be converted into equivalent 
TABLe 7: Calculated values for the phenolic insulation board.

\begin{tabular}{lcccccc}
\hline Mass moisture content (\%) & 808.78 & 921.64 & 1632.53 & 2782.25 & 3080.29 & 3763.91 \\
\hline$G_{\mathrm{v}}(\%)$ & 14.46 & 21.44 & 30.43 & 57.15 & 62.81 & 71.89 \\
\hline
\end{tabular}

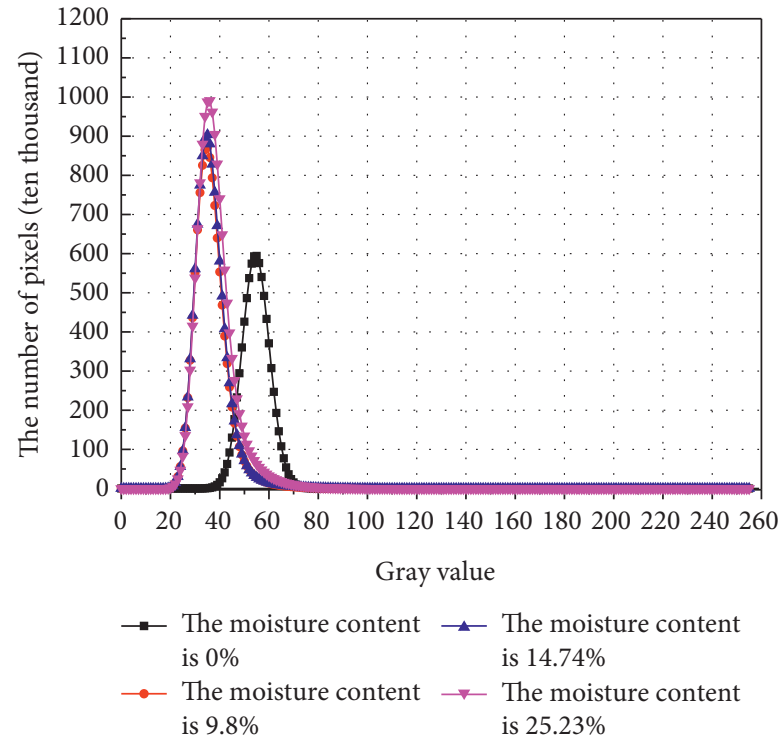

FIGURE 12: Gray histogram of the polyurethane thermal insulation board with different water contents.

TABle 8: Comparison of two algorithms for the polyurethane insulation board.

\begin{tabular}{lccc}
\hline Mass moisture content (\%) & 9.80 & 14.74 & 25.23 \\
\hline$\omega_{v}$ & 0.34 & 0.51 & 0.87 \\
$G_{\mathrm{V}}$ & 0.30 & 0.51 & 0.91 \\
\hline
\end{tabular}

heat conduction, and the effective thermal conductivity of porous materials can be determined using the macroscopic condition described by Fourier's law. In this study, the influence of moisture content on the thermal conductivity of materials is the effective thermal conductivity obtained by the equivalent internal heat transfer of water content materials to thermal conductivity.

The thermal conductivity of the phenolic insulating board and peeled polyurethane insulating board under dry conditions was evaluated using the Hot Disk thermal physical property analyzer. The results are listed in Table 9.

The self-made quasi-steady-state method was used to evaluate the thermal conductivity of the insulation materials with different mass moisture contents. The test results are depicted in Figure 13.

As shown in Table 9, the phenolic insulation board and peeled polyurethane insulation board core have average thermal conductivities of 0.040 and $0.029 \mathrm{~W} /(\mathrm{m} \cdot \mathrm{K})$, respectively, as determined using the Hot Disk method. Figure 13 shows that the average thermal conductivity of the phenolic insulation board is $0.04019 \mathrm{~W} /(\mathrm{m} \mathrm{K})$ under dry conditions and $0.02982 \mathrm{~W} /(\mathrm{m} \mathrm{K})$ after peeling, which are larger than the results determined using the Hot Disk thermal conductivity analyzer, and the deviations are 3.19\% and $0.33 \%$, respectively. The difference in thermal conductivity between the two methods is less than $5 \%$. Therefore, the quasi-steady state method is a reliable technique to measure thermal conductivity.

As shown in Figure 13, for the phenolic insulation panels, the relationship between thermal conductivity and mass moisture content can be divided into three stages: rapid-growth stage, slow-growth stage, and sharply-increasing stage. In the first stage, the mass moisture content increases from $0 \%$ to $1000 \%$, and the increase in amplitude of thermal conductivity is $78.57 \%$. In the second stage, the mass moisture content increases from $1000 \%$ to $2200 \%$, and the increase in amplitude of thermal conductivity is $46.48 \%$. In the third stage, the mass moisture content increases from $2200 \%$ to $3500 \%$, and the increase in amplitude of thermal conductivity is $134.78 \%$. The relationship between thermal conductivity and mass moisture content of the phenolic insulation board is approximately parabolic. For the polyurethane insulation board, the relationship between thermal conductivity and mass moisture content is approximately linear, and when mass moisture content increases from $0 \%$ to $24 \%$, the thermal conductivity growth rate is $68.76 \%$.

In engineering, the relationship between the mass moisture content and thermal conductivity of porous building materials is usually expressed as a linear function, as follows [42-44]:

$$
\lambda_{\mathrm{e}}=\lambda_{\mathrm{d}}+a^{\prime} \omega
$$

where $\lambda_{\mathrm{e}}$ is the effective thermal conductivity (unit is $\mathrm{W} /$ $(\mathrm{m} \cdot \mathrm{K})) ; \lambda_{\mathrm{d}}$ is the thermal conductivity of dry materials (unit is $\mathrm{W} /(\mathrm{m} \cdot \mathrm{K})$ ); $\omega$ is the moisture content (unit is $\mathrm{kg} / \mathrm{kg}$ ); and $a^{\wedge \prime}$ is the empirical constant.

Therefore, when the mass moisture content of the phenolic insulation board is small, the thermal conductivity can be derived from the aforementioned linear relationship; however, when the water content is high, the formula is no longer applicable. The power function can be used to approximate the relationship between mass moisture content and thermal conductivity, as follows:

$$
\lambda_{\mathrm{e}}=\lambda_{\mathrm{d}}+b^{\prime} \omega^{c}
$$

where $b^{\wedge}$ and $c^{\wedge \prime}$ are the fitting coefficients.

In Figure 14, the power function and linear function are used to fit the relationship between the mass moisture content and thermal conductivity of the phenolic insulation board and peeled polyurethane insulation board, respectively, and the correlation coefficient of the fitting results is higher. The thermal conductivity of the phenolic insulation board and peeled polyurethane insulation board can be predicted using the fitting formula in accordance with the mass moisture content of the material. The prediction formulas are as follows: 
TABLE 9: Testing parameters determined using the Hot Disk method.

\begin{tabular}{lcccccccc}
\hline \multirow{2}{*}{ Sample number } & \multicolumn{4}{c}{ Thermal conductivity $\mathrm{W} /(\mathrm{m} \cdot \mathrm{K})$} & \multicolumn{2}{c}{ Standard deviation } & RSD (\%) \\
& 1 & 2 & 3 & 4 & 5 & Average value & \\
\hline Phenolic & 0.04055 & 0.03953 & 0.04047 & 0.03955 & 0.04109 & 0.04006 & 0.0005 \\
Peeled polyurethane & 0.02993 & 0.02855 & 0.02781 & 0.02999 & 0.02821 & 0.02890 & 0.001 \\
\hline
\end{tabular}

Note: RSD is the relative standard deviation, which can be used to analyze the accuracy of the results.

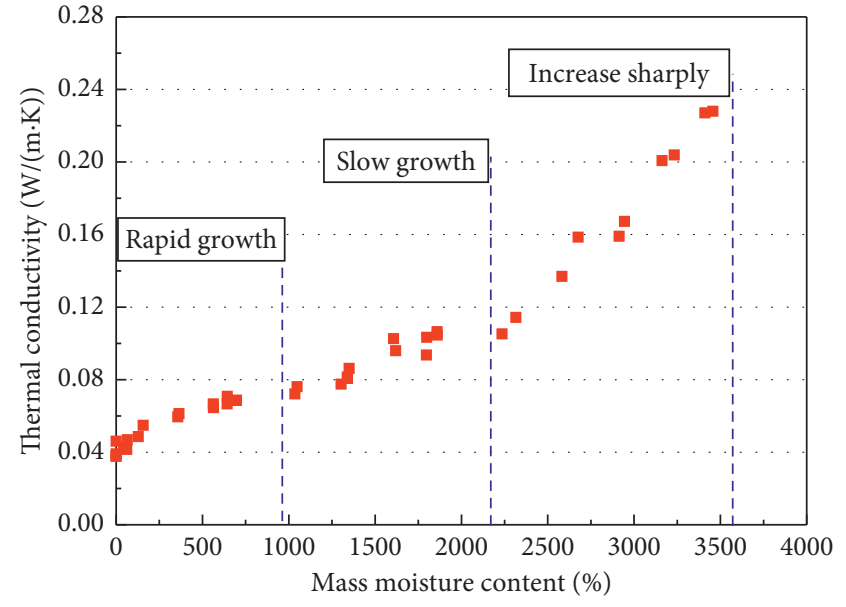

(a)

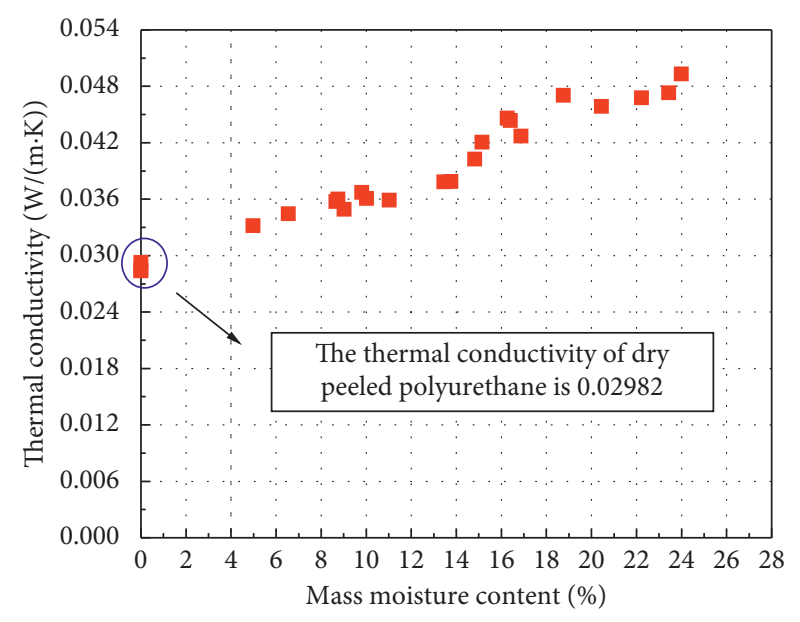

(b)

Figure 13: Thermal conductivity curves of different thermal insulation materials with different water contents. (a) Phenolic insulating board. (b) Peeled polyurethane insulating board.

Phenolic insulation board $\lambda_{\mathrm{e}}=0.05019+3.88472$

$$
\times 10^{-9} \omega^{2.63552}
$$

Peeled polyurethane insulation board $\lambda_{\mathrm{e}}=0.02882+8.59096$

$$
\times 10^{-4} \omega \text {. }
$$

3.4. Relationship between Thermal Conductivity and Gray Volume Moisture Content of Thermal Insulation Materials. The relationship between mass moisture content and thermal conductivity of thermal insulation materials only shows the influence of water content on thermal conductivity but not the influence of water distribution on thermal conductivity. Gv is derived from the gray value of the scanned image, which can describe the distribution of water in the insulation material. The relationship between Gv and thermal conductivity is equivalent to describing the influence of pore water distribution on thermal conductivity.

3.4.1. Relationship between Thermal Conductivity and Gv of the Water-Containing Thermal Insulation Materials. As shown in Table 8, Gv, which corresponds to the different mass moisture content of the phenolic insulation board and peeled polyurethane insulation board, can be obtained, and the thermal conductivity of the phenolic insulation board and peeled polyurethane insulation board with different mass moisture contents can be predicted using the fitting formula. Therefore, the power function can be used to fit the relationship between the thermal conductivity and Gv of the phenolic insulation board, and the one-dimensional firstorder equation can be used to fit the relationship between the thermal conductivity and Gv of the peeled polyurethane insulation board. The unified fitting formulas are as follows:

$$
\lambda_{\mathrm{e}}=\lambda_{\mathrm{d}}+m^{\prime} \omega^{n^{\prime}}
$$

where $\mathrm{m}^{\wedge}$ and $\mathrm{n}^{\wedge \prime}$ are the fitting coefficients.

The relationships between the thermal conductivity and Gv of the phenolic insulation board and peeled polyurethane insulation board are depicted in Figure 15 and expressed as follows:

$$
\begin{aligned}
& \lambda_{\mathrm{d}}=0.04019+1.08285 \times 10^{-4} x^{1.76155} \\
& \lambda_{\mathrm{d}}=0.03082+2.0928 \times 10^{-2} x
\end{aligned}
$$

3.4.2. Relationship between Thermal Conductivity and Gv of Ice-Containing Thermal Insulation Materials. The trend of change in ambient temperature in the tunnel is described by the sine function (Figure 16) [45]. When the air temperature in tunnels in cold areas is below zero, the thermal insulation material after water absorption freezes under low-temperature conditions. The thermal conductivity of ice is $2.24 \mathrm{~W} /$ $(\mathrm{m} \cdot \mathrm{K})$, which is about four times that of water. Therefore, the thermal conductivity of ice-containing thermal insulation 


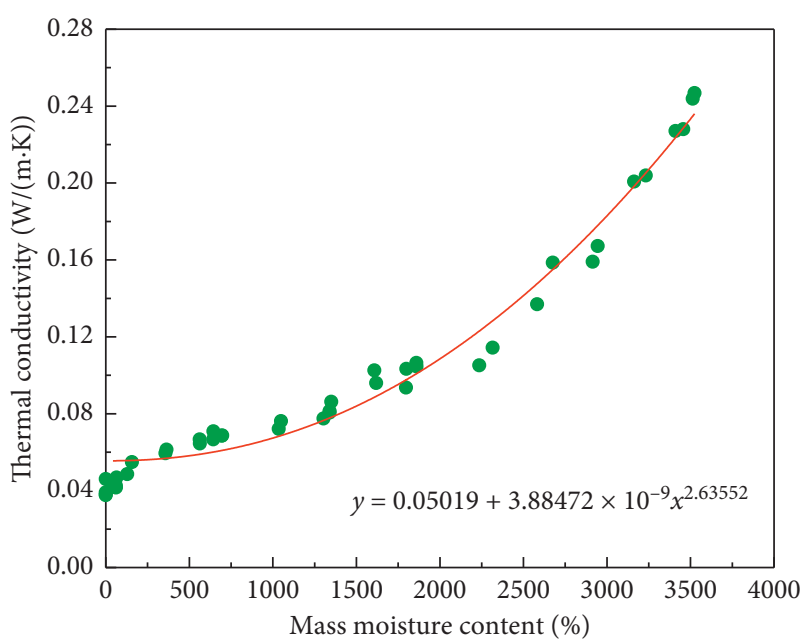

- Experimental data - Fitting curve

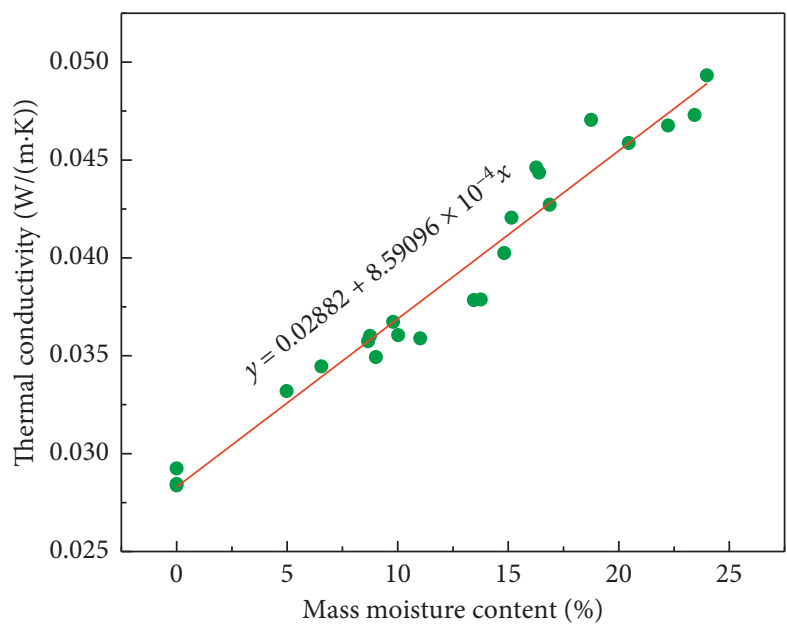

- Experimental data Fitting curve

FIGURE 14: Fitting analysis of the thermal conductivity of different thermal insulation materials. (a) Phenolic insulating board. (b) Peeled polyurethane insulating board.

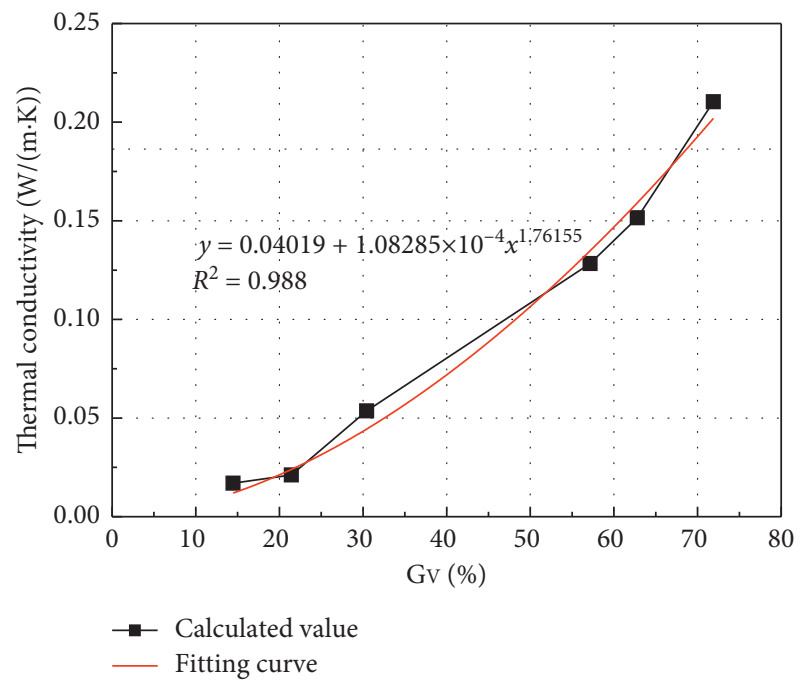

(a)

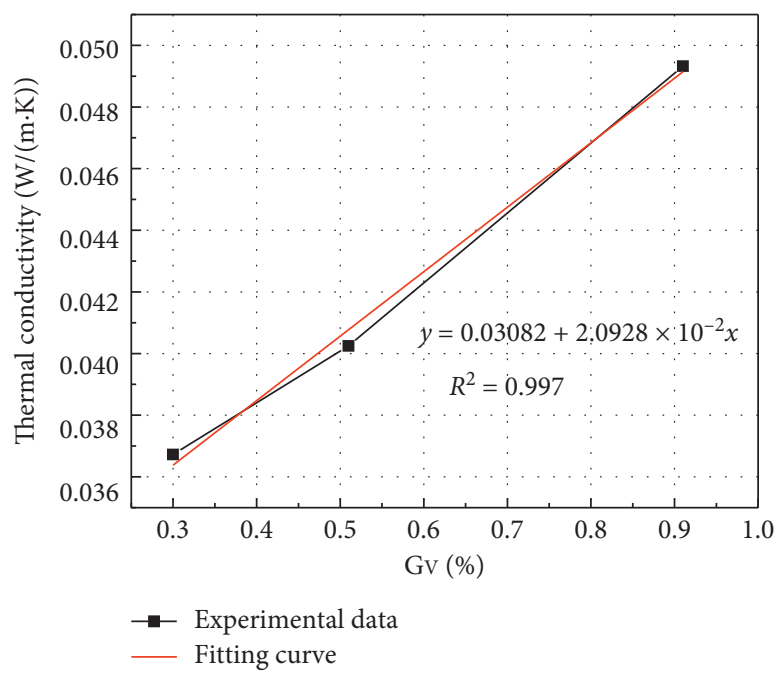

(b)

FIGURE 15: Fitting analysis of the thermal conductivity of different thermal insulation materials. (a) Phenolic insulation board. (b) Peeled polyurethane insulation.

materials is greater, worsening the effect of thermal insulation materials [46-53].

To calculate the thermal conductivity of the phenolic insulation board on the basis of Gv, Gv is multiplied by the thermal conductivity of water, and the residual drying volume ratio is multiplied by the thermal conductivity of the specimen during drying. By dividing the calculated thermal conductivity by the thermal conductivity determined using the fitting formula, the corresponding proportion is obtained. In accordance with this ratio, when water becomes ice, the thermal conductivity of the ice-containing phenolic insulation board is the value calculated by substituting the thermal conductivity of water with the thermal conductivity of ice, multiplied by the corresponding ratio. This value is used to estimate the overall thermal conductivity of watercontaining phenolic insulation panels after freezing. The calculation results are listed in Table 10 .

By using the same method to calculate the thermal conductivity of the ice-containing polyurethane insulation board, the thermal conductivity of the ice-containing peeled polyurethane insulation board is determined. The results are listed in Table 11. 


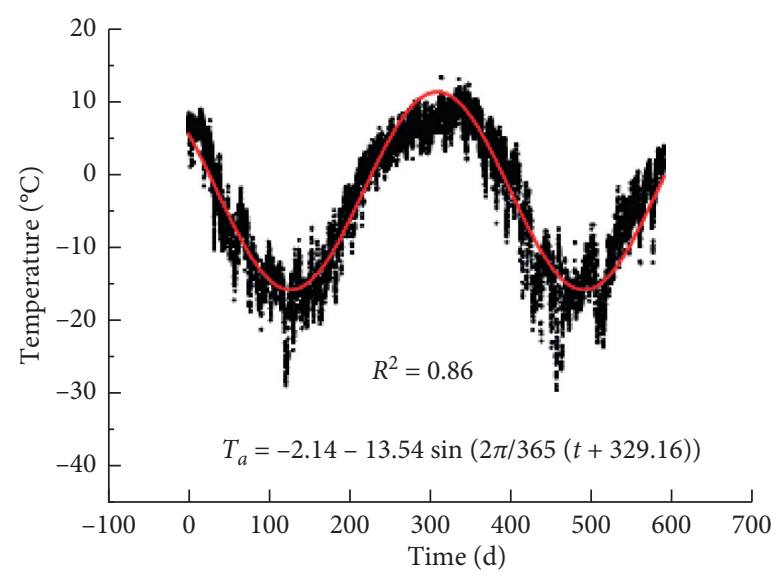

FIGURE 16: Air temperature at the entrance of the Yuximolegai tunnel [45].

TABLE 10: Ice-containing thermal conductivity of the phenolic thermal insulation board.

\begin{tabular}{|c|c|c|c|c|c|c|}
\hline Gv (\%) & 14.46 & 21.44 & 30.43 & 57.15 & 62.81 & 71.89 \\
\hline Ice-containing thermal conductivity $(\mathrm{W} /(\mathrm{m} \cdot \mathrm{K}))$ & 0.1761 & 0.2049 & 0.3320 & 0.6406 & 0.7346 & 0.9697 \\
\hline
\end{tabular}

TABle 11: Thermal conductivity of ice-containing peeled polyurethane insulation board.

\begin{tabular}{lccc}
\hline Gv $(\%)$ & 0.30 & 0.51 & 0.91 \\
\hline $\begin{array}{l}\text { Ice-containing thermal conductivity } \\
(\mathrm{W} /(\mathrm{m} \cdot \mathrm{K}))\end{array}$ & 0.0439 & 0.0534 & 0.0734 \\
\hline
\end{tabular}

\section{Conclusions}

(1) CT images of the phenolic insulation board and polyurethane insulation board were obtained. The concept of Gv is proposed by using the gray value of the CT scanning image, which can better describe the distribution of pore water in thermal insulation materials. By comparing $\mathrm{Gv}$ with the volume moisture content, the relationship between the mass moisture content and Gv is established.

(2) The accuracy of the self-made quasi-steady state tester is verified by evaluating the thermal conductivity of the dry insulation material. The advantage of the self-made quasi-steady state tester is that it can measure the thermal conductivity of the thermal insulation material with water content. Thus, the relationship between the mass moisture content and thermal conductivity of the phenolic thermal insulation board and polyurethane thermal insulation board can be determined.

(3) The relationship between Gv and thermal conductivity of materials is evaluated based on the relationship between the mass moisture content and thermal conductivity of thermal insulation materials. A method to predict thermal conductivity is not only proposed innovatively; the influence of pore water distribution on the thermal conductivity of thermal insulation materials is also described.

\section{Data Availability}

The test data used to support the findings of this study are included within the article and can be made freely available.

\section{Conflicts of Interest}

The authors declare that they have no conflicts of interest.

\section{Acknowledgments}

This study was supported by the National Natural Science Fund of China (Grant no. 51378071) and Natural Science Foundation of Shaanxi Province of China (Grant no.21302116-0351). The authors are grateful to the researchers for their support for the experimental study.

\section{References}

[1] N. I. Johansen, S. L. Huang, and N. B. Aughenbaugh, "Alaska's crrel permafrost tunnel," Tunnelling and Underground Space Technology, vol. 3, no. 1, 1988.

[2] Y. Lai, S. Liu, Z. Wu, and W. Yu., "Approximate analytical solution for temperature fields in cold regions circular tunnels," Cold Regions Science and Technology, vol. 34, no. 1, pp. 43-49, 2002.

[3] Y. M. Lai, H. Wu, Z. W. Wu et al., "Analytical viscoelastic solution for frost force in cold-region tunnels," Cold Regions Science and Technology, vol. 31, no. 3, 2000.

[4] Y. M. Lai, X. F. Zhang, W. B. Yu, Z. Q. Liu, and J. Z. Xiao, "Three-dimensional nonlinear analysis for the coupled problem of the heat transfer of the surrounding rock and the heat convection between the air and the surrounding rock in cold-region tunnel," Tunnelling and Underground Space Technology, vol. 20, no. 4, 2005.

[5] T. Mimouni, F. Dupray, and L. Laloui, "Estimating the geothermal potential of heat-exchanger anchors on a cut-andcover tunnel," Geothermics, vol. 51, 2014. 
[6] L. L. Liu, Z. Li, X. Liu et al., "Frost front research of a coldregion tunnel considering ventilation based on a physical model test," Tunnelling and Underground Space Technology, vol. 77, 2018.

[7] J. X. Lai, J. L. Qiu, H. B. Fan et al., "Freeze-proof method and test verification of a cold region tunnel employing electric heat tracing," Tunnelling and Underground Space Technology, vol. 60, 2016.

[8] S. B. Zhang, S. Y. He, J. L Qiu, W. Xu et al., "Displacement characteristics of a urban tunnel in silty soil by shallow tunnelling method," Advances in Civil Engineering, vol. 2020, Article ID 3975745, 2020.

[9] T. Liu, Y. J. Zhong, Z. H. Feng et al., "New construction technology of a shallow tunnel in boulder-cobble mixed grounds," Advances in Civil Engineering, vol. 2020, Article ID 5686042, 2020.

[10] Q. Jiang, F. Yan, J. Wu, Q. Fan, S. Li, and D. Xu, "Grading opening and shearing deformation of deep outward-dip shear belts inside high slope: a case study," Engineering Geology, vol. 250, pp. 113-129, 2019.

[11] S. S. Xu, J. L. Qiu, L. X. Wang et al., “Automatic monitoring system in underground engineering construction: review and prospect," Advances in Civil Engineering, Article ID 3697253, 2020.

[12] X. J. Tan, W. Z. Chen, H. D. Yu, and D. D. Liu, "Study of temperature field of tunnel surrounding rock in cold regions considering effect of ventilation and length design of insulation material," Chinese Journal of Rock Mechanics \& Engineering, vol. 32, no. 7, 2013.

[13] Z. Hu, H. Ding, J. Lai, H. Wang, X. Wang, and S. He, "The durability of shotcrete in cold region tunnel: a review," Construction and Building Materials, vol. 185, pp. 670-683, 2018.

[14] Q. Jiang, G. Su, X.-T. Feng, G. Chen, M.-Z. Zhang, and C. Liu, "Excavation optimization and stability analysis for large underground caverns under high geostress: a case study of the Chinese Laxiwa project," Rock Mechanics and Rock Engineering, vol. 52, no. 3, pp. 895-915, 2019.

[15] J. Lai, J. Chen, H. Fan, and K. Wang, "New technology and experimental study on snow-melting heated pavement system in tunnel portal," Advances in Materials Science and Engineering, vol. 2015, Article ID 706536, 11 pages, 2015.

[16] X. Liu, G. Cai, S. Liu, and A. J. Puppala, "Thermo-hydromechanical properties of bentonite-sand-graphite-polypropylene fiber mixtures as buffer materials for a high-level radioactive waste repository," International Journal of Heat and Mass Transfer, vol. 141, pp. 981-994, 2019.

[17] L. Liu, G. Cai, X. Liu et al., "Evaluation of thermal-mechanical properties of quartz sand-bentonite-carbon fiber mixtures as the borehole backfilling material in ground source heat pump," Energy and Buildings, vol. 202, Article ID 109407, 2019.

[18] Y. Zhou, X. Zhang, and J. Deng, “A mathematical optimization model of insulation layer's parameters in seasonally frozen tunnel engineering," Cold Regions Science and Technology, vol. 101, pp. 73-80, 2014.

[19] G. Cheng, J. Zhang, Y. Sheng et al., "Principle of thermal insulation for permafrost protection," Cold Regions Science and Technology, vol. 40, no. 1-2, pp. 0-79, 2004.

[20] C. C. Xia, D. F. Fang, Q. Li et al., "An approach for determining length of insulation layer in cold region tunnels," Journal of Tong ji University, vol. 44, no. 9, 2016.

[21] C. C. Xia and C. L. Han, "Study on computing method of thermal-protective coating 's laying depth for different types of permafrost in tunnels in cold regions," China Journal of Highway and Transport, vol. 26, no. 5, 2013.

[22] S. He, L. Y. Chao, and F. M. Jun, "Numerical analysis of optimization design for insulation layer in cold regions tunnel," Advanced Materials Research, vol. 1065-1069, 2014.

[23] P. Qi, J. Zhang, Z. R. Mei, and Y. X. Wu, "Study on the range of freeze-thaw of surrounding rock from a cold-region tunnel and the effects of insulation material," Advanced Materials Research, vol. 399-401, pp. 2222-2225, 2011.

[24] S. Zhang, Y. Lai, X. Zhang, Y. Pu, and W. Yu, "Study on the damage propagation of surrounding rock from a cold-region tunnel under freeze-thaw cycle condition," Tunnelling and Underground Space Technology, vol. 19, no. 3, pp. 295-302, 2004.

[25] Y. Wang, S. H. Zhang, D. T. Niu et al., "Strength and chloride ion distribution brought by aggregate of basalt fiber reinforced coral aggregate concrete," Construction and Building Materials, vol. 234, Article ID 117390, 2020.

[26] Q. X. Yan, B. J. li, and Y. Y. Zhang, "Numerical investigation of heat-insulating layers in a cold Region tunnel, taking into account airflow and heat transfer," Applied Science Basel, vol. 7, no. 7, 2017.

[27] S. Huang, Q. Liu, A. Cheng, and Y. Liu, “A statistical damage constitutive model under freeze-thaw and loading for rock and its engineering application," Cold Regions Science and Technology, vol. 145, pp. 142-150, 2018.

[28] S. Li, F. Niu, Y. Lai et al., "Optimal design of thermal insulation layer of a tunnel in permafrost regions based on coupled heat-water simulation," Applied Thermal Engineering, vol. 110, 2017.

[29] X. Zhang, Y. Lai, W. Yu, and Y. Wu, "Forecast analysis for the re-frozen of Feng Huoshan permafrost tunnel on Qing-Zang railway," Tunnelling and Underground Space Technology, vol. 19, no. 1, pp. 45-56, 2004.

[30] Y. Y. Li, Y. M. Sun, J. L. Qiu et al., "Moisture absorption characteristics and thermal insulation performance of thermal insulation materials for cold region tunnels," Construction and Building Materials, vol. 237, Article ID 117765, 2020.

[31] Y. C. Zheng, Y. H. Zhang, L. X. Wang, K. Wang, and T. Liu, "Mechanical reinforcement mechanism of steel fiber reinforced concrete and its application in tunnels," Advances in Civil Engineering, vol. 2020, Article ID 3479475, 16 pages, 2020.

[32] J. X. Lai, X. L. Wang, J. L. Qiu et al., “A state-of-the-art review of sustainable energy based freeze proof technology for coldregion tunnels in China," Renewable and Sustainable Energy Reviews, vol. 82, 2018.

[33] Q. G. Ma, X. X. Luo, and Y. M. Lai, "Numerical investigation on thermal insulation layer of a tunnel in seasonally frozen regions," Applied Thermal Engineering, vol. 138, 2018.

[34] S. Zahia, B. Dominique, N. Naim et al., "Thermal properties of new insulating Juncus maritimus fibrous mortar composites/ experimental results and analytical laws," Applied SciencesBasel, vol. 9, no. 5, p. 981, 2019.

[35] B. Lahcen, B. Mustapha, H. Hassan, B. Brahim, and N. Fatima Ait, "Moisture content influence on the thermal conductivity of insulating building materials made from date palm fibers mesh," Construction and Building Materials, vol. 148, 2017.

[36] Z. Pavlšk, L. Fiala, and R. Cerný, "Experimental assessment of thermal conductivity of a brick block with internal cavities using a semi-scale experiment," International Journal of Thermophysics, vol. 34, no. 5, pp. 909-915, 2013. 
[37] L. Bodnarova, J. Hroudova, J. Zach et al., "Determination of thermal conductivity on lightweight concretes," Key Engineering Materials, vol. 677, 2016.

[38] T. Liu, X. Xu, and J. Yang, "Experimental study on the effect of freezing-thawing cycles on wind erosion of black soil in Northeast China," Cold Regions Science and Technology, vol. 136, 2017.

[39] W. Pei, W. Yu, S. Li et al., "A new method to model the thermal conductivity of soil-rock media in cold regions: an example from permafrost regions tunnel," Cold Regions Science and Technology, vol. 95, 2013.

[40] A. V. Luikov, Heat and Mass Transfer, Mir Publishers, Moscow, Russia, 1980.

[41] B. O. Aduda, "Effective thermal conductivity of loose particulate systems," Journal of Materials Science, vol. 31, no. 24, pp. 6441-6448, 1996.

[42] M. G. Gomes, I. Flores-Colen, L. M. Manga, A. Soares, and J. de Brito, "The influence of moisture content on the thermal conductivity of external thermal mortars," Construction and Building Materials, vol. 135, pp. 279-286, 2017.

[43] M. Khoukhi, "The combined effect of heat and moisture transfer dependent thermal conductivity of polystyrene insulation material: impact on building energy performance," Energy and Buildings, vol. 169, pp. 228-235, 2018.

[44] W. W. Liu, Q. Feng, C. X. Wang et al., "Analytical solution for three-dimensional radial heat transfer in a cold-region tunnel," Cold Regions Science and Technology, vol. 164, 2019.

[45] X. L. Wang, J. X. Lai, J. L. Qiu, W. Xu, L. X. Wang, and Y. B. Luo, "Geohazards, reflection and challenges in mountain tunnel construction of China: a data collection from 2002 to 2018," Geomatics, Natural Hazards and Risk, vol. 11, no. 1, pp. 667-675, 2020.

[46] Y. Zhu, X. Huang, J. Jia et al., "Experimental study on the thermal conductivity for transmission line icing," Cold Regions Science and Technology, vol. 129, pp. 96-103, 2016.

[47] D. Francesco, B. Giorgio, B. Francesco, S. Sara, and R. Alessandra, "Experimental assessment of the water content influence on thermo-acoustic performance of building insulation materials," Construction and Building Materials, vol. 158, pp. 264-274, 2018.

[48] T. Liu, Y. J. Zhong, Z. Han, and W. Xu, "Deformation characteristics and countermeasures for a tunnel in difficult geological environment in NW China," Advances in Civil Engineering, vol. 2020, Article ID 1694821, 16 pages, 2020.

[49] Z. Zhou, Y. Dong, P. Jiang, D. Han, and T. Liu, "Calculation of pile side friction by multiparameter statistical analysis," Advances in Civil Engineering, vol. 2019, Article ID 2638520, 12 pages, 2019.

[50] Z. P. Song, G. L. Shi, B. Y. Zhao, K. M. Zhao, and J. B. Wang, "Study of the stability of tunnel construction based on doubleheading advance construction method," Advances in $\mathrm{Me}$ chanical Engineering, vol. 12, no. 1, p. 17, 2020.

[51] C. Liu, L. Xing, H. W. Liu et al., "Numerical study of bond slip between section steel and recycled aggregate concrete with full replacement ratio," Applied Sciences, vol. 10, no. 3, Article ID $887,2020$.

[52] L. X. Wang, C. H. Li, J. L. Qiu, K. Wang, and T. Liu, "Treatment and effect of loess metro tunnel mersion environment," Gunder surrounding pressure and water imeofluids, vol. 2020, Article ID 7868157, 15 pages, 2020.

[53] Y. Zheng, J. Xiong, T. Liu, X. Yue, and J. Qiu, "Performance of a deep excavation in Lanzhou strong permeable sandy gravel strata," Arabian Journal of Geosciences, vol. 13, no. 4, 17 pages, 2020. 